\title{
“LER, ESCREVER E CONTAR": ENTRE CIRCULAÇÃO E APROPRIAÇÕES DE MÉTODOS NA ESCOLA PRIMÁRIA DO MÉDIO SERTÃO SERGIPANO (1930-1961)
}

\author{
R. A. D. N. BARRETO, I. M. MESQUITA, R. R. N. SILVA
}

Universidade Tiradentes (Unit), Universidade Tiradentes (Unit), Universidade Estadual Paulista (Unesp)

raylanenavarro@bol.com.br

\section{RESUMO}

O presente artigo busca compreender indícios da circulação, as apropriações e as adequações dos métodos de ensino para leitura, escrita e cálculo na escola primária no território do Médio Sertão sergipano, no arco de tempo que compreende 1930 a 1961. Para empreender tal pesquisa, examinamos os documentos oficiais em diálogo com a metodologia da história oral. Constatamos que muito embora no estado de Sergipe circulasse um plano discursivo modernizador, as apropriações e as adequações dos métodos de ensino se deram conforme as condições materiais e intelectuais do tempo e lugar.

PALAVRAS-CHAVE: Circulação, Apropriação, Métodos de ensino, Médio Sertão Sergipano.

\section{"READ, WRITE AND COUNT": BETWEEN CIRCULATION AND APPROPRIATION OF TEACHING METHODS IN PRIMARY SCHOOLS IN THE MEDIUM MIDLANDS OF SERGIPE (1930-1961)}

\begin{abstract}
This article seeks to understand the circulation, appropriations and adaptations of teaching methods for reading, writing and arithmetic in primary school in the medium midlands of Sergipe, between 1930 to 1961. To conduct such research, we study the official documents referring to the methodology of oral
\end{abstract}

history. We realize that although the State of Sergipe is circulating a modernizing discursive plan, appropriations and adaptations of teaching methods is given according to the material and intellectual conditions of time and place.

KEYWORDS:. Circulation, Appropriation, Teaching methods, Medium Midlands of Sergipe. 


\section{PRIMEIROS PASSOS PARA O DESLOCAMENTO}

"Eu disse a professora: - Quem muito ver, faz aprender."

(Moura, 2013).

O fragmento da narrativa do professor aposentado, Angelino Pereira de Moura, reverbera um caminho ${ }^{1}$ para chegar ao que queremos: compreender os indícios da circulação, as apropriações e as adequações dos métodos de ensino para leitura, escrita e cálculo na escola primária no território do Médio Sertão sergipano, entre 1930 e 1961 . Como pesquisar é viajar e para tal, escolhemos companheiros, bagagens e o destino, foi com esse propósito que levamos em nossas malas experiências vividas e, no trajeto, escrevemos em nosso diário de bordo o que foi rememorado pelos(as) nossos(as) entrevistados(as), impulsionando-nos a voltar às marcas deixadas na investida de pesquisa.

Esses rastros são resultados do projeto de pesquisa, Modos de Educar: Práticas escolares e cultura escolar no território do Médio Sertão sergipano². Nesta investida, trouxemos da viagem doze entrevistas ${ }^{3}$, transcritas e textualizadas, de professores(as) aposentados(as), com idade entre 67 e 87 anos. Chegamos até eles(as) através dos arquivos e registros armazenados nas Diretorias Regionais de Educação (DR) e Secretarias Municipais de Educação (SME), localizados nos seis municípios que compõem o território do Médio Sertão sergipano: Aquidabã, Graccho Cardoso, Cumbi, Feira Nova, Itabi e Nossa Senhora das Dores. Para operarmos com os relatos orais ${ }^{4}$, consideramos as recomendações deixadas por Alberti (2004) em seu Manual de História Oral, que orienta sobre as técnicas mobilizadas no ouvir e contar das narrativas e no fazer história oral, que:

[...] não é simplesmente sair com um gravador em punho, algumas perguntas na cabeça, e entrevistar aqueles que cruzam nosso caminho dispostos a falar um pouco sobre suas vidas. Essa noção simplificada pode resultar em um punhado de fitas gravadas, de pouca ou nenhuma utilidade, que permanecem guardadas sem que se saiba muito bem o que fazer com elas. Muitas vezes tal situação é criada por uma concepção talvez ingênua e certamente equivocada de que a história oral, em vez de meio de ampliação de conhecimento sobre o passado, é, digamos, o próprio passado reencarnado em fitas gravadas - como se o simples fato de

\footnotetext{
${ }^{1}$ A alegoria é pensada neste texto para representar o percurso da pesquisa.

${ }^{2}$ O projeto de pesquisa Modos de Educar: Práticas escolares e cultura escolar no território do Médio Sertão sergipano, derivou do projeto de pesquisa "guarda-chuva" Memória oral da educação sergipana, coordenado pela Prof.a Dr.a Raylane Andreza Dia Navarro Barreto. O projeto está dividido de acordo com as regiões do estado de Sergipe, perfazendo um total de oito subprojetos. O objetivo era compreender como se constituíram os modos de educar de educadores atuantes no estado de Sergipe. Para tanto, foi necessário: mapear os educadores mais idosos e de maior representatividade na área educacional; identificar as práticas escolares; e analisar a cultura de escola que fora produzida nas instituições educativas. O propósito era possibilitar a produção de saberes e entendimentos acerca dos modos de educar e dos métodos de ensino, fomentando interações e trocas no âmbito da pesquisa e do conhecimento, envolvendo instituições de ensino, grupos de pesquisas, discentes, docentes e pesquisadores relacionados a áreas afins. O projeto foi financiado pelo CNPq. Edital MCTI/CNPq/MEC/CAPES. N. 18/2012. № do processo 405366/2012-4. O projeto também contou com bolsas de Iniciação científica PIBIC/CNPq e PROBIC/Unit.

${ }^{3}$ Estas se encontram armazenadas no acervo digital, que constituirá o Centro de Memória da Educação Sergipana onde serão somadas as outras 133 entrevistas audiovisuais decorrentes dos demais subprojetos.

${ }^{4}$ As entrevistas foram cedidas pelos professores, a partir da Carta de Cessão de direitos, dispondo sobre os direitos e deveres do entrevistado, bem como o esclarecimento, sobre uso das entrevistas para fins de pesquisa acadêmica. As entrevistas foram gravadas em áudio e vídeo, sua duração soma o montante de $24 \mathrm{~h} / \mathrm{s}$ e foram devidamente transcritos em Microsoft Word 2010.
} 
deixar registrados depoimentos de atores e/ou testemunhas do passado eximisse o pesquisador da atividade de pesquisa. (Alberti, 2004, p. 29).

Ao cumprir a etapa do gravado, partimos para produção do conhecimento que, por sua vez, necessita de esforço pela sistematização dos fatos, porque a construção narrativa projetada pela fala dos(as) entrevistados(as) não é linear e tranquila, mas é similar a um mosaico do qual podem surgir várias imagens interpretativas (Mesquita; Barreto e Silva, 2013). E nesse sentido, a metodologia da História Oral ultrapassa o modelo de simples coleção de histórias pessoais e se transforma em diálogo com o passado, estimulando outras interpretações históricas.

A fim de compor mais e melhor nosso objeto de estudo, também seguimos as trilhas deixadas pelo pó dos documentos oficias dispostos no Arquivo Público Estadual de Sergipe 5 . Foram utilizados para a realização deste estudo as Mensagens de Governadores do Estado e os Relatórios Anuais, no período que compreende 1930 a 1961. Ao lermos esses documentos, usamos as lentes do historiador Jacques Le Goff, em diálogo com o filósofo Michel Foucault, o qual advertiu: "Não existe um documento-verdade. Todo o documento é mentira." (Le Goff, 1996, p. 547-548). Somos conduzidos por esta máxima do documento/monumento para considerar que todo documento consiste em sinais, resquícios, impressões e, sobretudo, é o resultado de uma construção social e, por isso, possui relações de poder. Por certo, quando nossos olhos leram o que estava escrito nas páginas amareladas dos documentos, tivemos a intenção de despi-los de suas roupagens e da sua suposta aparência.

Nessa alternância de fontes seguimos evidências, ora deixadas pelos documentos oficiais, ora pelas narrativas dos(as) professoras(as), estabelecendo diálogos. Tais evidências foram fruto de perguntas levantadas por nós pesquisadores, pois segundo Albuquerque Júnior (2007) "O que se chama de evidência é fruto de perguntas que se fazem ao que está posto e ao fato de que, ao serem problematizados pelo historiador, transformam-se, em larga medida, em sua criação." (Albuquerque Júnior, 2007, p. 63). Desse modo, interrogamos: Quis os indícios da circulação dos métodos de ensino para leitura, escrita e cálculo na escola primária no território do Médio Sertão sergipano? Como esses(as) professores(as) se apropriaram das novas proposições pedagógicas? Houve adequações entre as práticas já sedimentadas e os novos métodos? Qual era o alcance dos cursos de formação? Para responder tais questões, seguimos nosso trajeto pelos pressupostos teóricos da História Cultural Francesa.

No início do século XX, despontou no horizonte da historiografia diversas transformações do conhecimento histórico, em decorrência das mudanças de paradigmas ${ }^{6}$. Tal renovação permitiu que carregássemos em nossa bagagem a noção de apropriação, oferecida pelo historiador francês Roger Chartier, que: "[...] tem por objectivo uma história social das interpretações, remetidas para as suas determinações fundamentais (que são sociais, institucionais e culturais) e inscritas nas práticas específicas que as produzem." (Chartier, 1990, p. 26). Ainda segundo o autor: "[...] a aceitação das mensagens e dos modelos opera-se sempre

\footnotetext{
${ }^{5}$ O Arquivo Público Estadual de Sergipe (APES) está localizado na Praça Fausto Cardoso, no 348. Bairro: Centro. CEP: 49015-000 - Aracaju/ SE.

${ }^{6}$ Parafraseando Sandra Pesavento (2005) o historicismo de Ranke e o positivismo de Comte foram revistos no início do século XX, tanto pelo marxismo como pela escola dos Annales. Ou seja, foi ainda de dentro da vertente neomarxista inglesa e da história francesa dos Annales que veio o impulso de renovação, resultando na abertura desta nova corrente historiográfica a que chamamos de História Cultural ou mesmo de Nova História Cultural.
} 
através de ordenamentos, de desvios, de reempregos singulares que são o objecto fundamental da história cultural. (Chartier, 1990, p.136), pois deste modo, pensar:

[...] as apropriações culturais permitem também que não se considerem totalmente eficazes nem radicalmente aculturantes os textos ou as palavras que pretendem moldar os pensamentos e as condutas. As práticas que deles se apoderam são sempre criadoras de usos ou de representações que não são de forma alguma redutíveis à vontade dos produtores de discursos e normas. (Chartier, 1990, p. 136).

O autor reafirmou a emergência de novas noções e objetos no seio da historiografia, permitindo uma dilatação do campo de trabalho do historiador e o diálogo com outros campos de conhecimento, inclusive com a Educação. Desse modo, por meio da noção de apropriação, é possível também compreender como em uma determinada época se produz e se interpreta uma realidade social.

\section{OS VENTOS DA MODERNIDADE PEDAGÓGICA: ENTRE INOVAÇÕES E PERMANÊNCIAS}

$\mathrm{Na}$ segunda metade do século XIX sopravam em terras brasileiras os ventos da modernidade pedagógica, advindos da Europa e dos Estados Unidos da América. Ventos que serviram de inspiração para o políticos, educadores e intelectuais, que propuseram uma renovação educacional, por meio da reforma dos métodos de ensino e dos mestres. Segundo Mortatti (2000), em sua tese de Livre-Docência (Magnani, 1997), publicada no livro Os sentidos da alfabetização: São Paulo 1876 - 1992, para fins de demarcação cronológica, a história dos métodos de alfabetização no Brasil foram divididos em quatro ${ }^{7}$ momentos.

A constituição de um discurso renovador da escola brasileira se fazia pela tônica do "novo" e para tanto era necessário o abandono do "tradicional". Já nas últimas décadas do século XIX, diversas mudanças afirmadas como novidades pelo "escolanovismo" povoavam o imaginário da escola e eram perpassadas, como prescrições, nos textos dos relatórios de inspetores, nos preceitos legais e nos pareceres. (Vidal, 2000). Contudo, não seria fácil abandonar a cultura em voga nas escolas, aglutinadas no termo "tradicional". O que se chamou de "tradicional", traduziase em métodos de ensino e espaços escolares, os quais funcionavam, na maioria das vezes, nas casas dos professores ou de famílias, sobretudo, nas sedes de fazendas, revelando-se locais precários, sem condições adequadas para concretização dos modernos métodos de ensino que começaram a fervilhar na época.

\footnotetext{
${ }^{7}$ Esses momentos e suas principais características são os seguintes: primeiro momento crucial (1876 a 1890$)$ disputa entre defensores do então "novo" método da palavração e os dos "antigos" métodos sintéticos (alfabético, fônico, silábico); segundo momento crucial (1890 a meados da década de 1920) - disputa entre defensores do então "novo" método analítico e os dos "antigos" métodos sintéticos; terceiro momento crucial (meados dos anos de 1920 a final da década de 1970) - disputas entre defensores dos "antigos" métodos de alfabetização (sintéticos e analíticos) e os dos então "novos" "testes ABC para verificação da maturidade necessária ao aprendizado da leitura e escrita", criados por M. B. Lourenço Filho, de que decorreu a introdução dos "novos" métodos mistos; quarto momento crucial (meados da década de 1980 aos dias atuais) - disputas entre os defensores da então "nova" teoria construtivista e os dos "antigos" testes de maturidade e dos "antigos" métodos de alfabetização. A esse respeito, ver Mortatti (2016).

${ }^{8}$ As novidades do "escolanovovismo" consideravam a centralidade da criança na relação de aprendizagem, o respeito aos preceitos higienistas na disciplinarização do corpo do aluno e dos seus gestes, a cientificidade da escolarização de saberes e fazeres sociais e a exaltação do ato de observar, de intuir, na construção do conhecimento do aluno.
} 
A existência de escolas precárias foi observada na narrativa da professora Maria Ducineia Souza Santos, quando estudou na escola isolada", no povoado "Logradouro", atualmente município de "Feira Nova", por volta de 1935: "Era em uma casa. Tinha muito aluno, uns cinquenta em uma sala só. Mas aqui quando não tinha escola, papai ensinava em casa. Nesse tempo tinha o bê-á-bá e o $A B C^{10 "}$. (Santos, 2013). Quanto às condições metodológicas de ensino, as professoras entrevistadas aprenderam em salas multisseriadas, frequentadas por alunos de variadas faixas etárias e níveis de aprendizado. Entre os anos de 1940 e 1950, sobretudo no meio rural no estado de Sergipe, eram comuns escolas multisseriadas e unidocentes (escolas isoladas), ou seja, um só professor lecionava para todas as séries reunidas em uma única sala de aula. A professora dividia seu tempo ensinando a ler e a escrever às crianças, que tinham idades diferentes e cursavam séries também diversas.

A narrativa da professora nos apresenta o método de ensino utilizado em seu tempo e lugar e, que por sua vez, também se comunga com outros relatos, a exemplo, da professora Odete Vieira dos Santos, quando narrou sobre ensino das primeiras letras e a permanência de métodos tradicionais, a saber, o método sintético, na escola isolada, situada no povoado "Sítios Novos", município de Aquidabã, por volta de 1938:

[...] meu pai ensinou todo mundo lá em casa o $A B C$. Todo mundo apanhou para aprender as letras. Aí ele cobria assim [dobra a barra do vestido]. Ele [pai] dizia: 'Que letra é essa?' Se estivesse descoberto a gente lia né? Aí ele fazia, cobria com os dois dedos polegares. [...] Agora lá na escola ela [a professora 'Laudicéia'] fazia as letras para a gente cobrir. Esse $A B C$ era um livro bem fininho. Tinha as letras maiúsculas e as letras minúsculas. Eu decorei. Depois de decorar as cinco vogais eu comecei a decorar as consoantes. Depois tinha que soletrar. A gente dava soletrando e por extenso: 'bê-á-bá'. A gente soletrava e dizia: 'ba-be-bi-bo-bu.' (Santos, 2013).

A narrativa acima nos dá a ver um ensino alicerçado na aprendizagem pela memória, priorizando a abstração, a verbalização e a repetição. Para tanto, fazia-se necessário o conhecimento dos sons, primeiro das vogais, depois das consoantes, seguindo uma lógica crescente de dificuldade, consistindo no método de alfabetização sintético. Para Mortatti (), em seu texto A "querela dos métodos" de alfabetização no Brasil: contribuições para metodizar o debate, os métodos de alfabetização, como se sabe:

[...] podem ser classificados em dois tipos básicos: sintético (da "parte" para o "todo") e analítico (do "todo" para a "parte"). Dependendo do que foi considerado a unidade linguística a partir da qual se devia iniciar o ensino da

\footnotetext{
${ }^{9}$ O termo "escola isolada" denomina um modelo de escola unidocente e multisseriada. Sabe-se que tais unidades, ao contrário das escolas reunidas e grupos escolas, muitas vezes localizavam-se no meio rural e caracterizavam-se por serem precárias em sua estrutura. Santos (2016) demostrou em sua dissertação Por uma história vista de baixo: as escolas primárias dos territórios do centro e sul do estado de Sergipe (1930 - 1960), que para além do que circulou no campo das ideais, as escolas isoladas, caracterizadas pelas condições precárias de funcionamento e manutenção, sobreviveram ao tempo e às mudanças educativas, compondo um modelo heterogêneo de escolarização, em que coexistiram matrizes antigas e novos tipos de escolas ao menos durante as seis primeiras décadas do século XX, e possivelmente em todo o século.

${ }^{10}$ Geralmente iniciava-se o ensino da leitura com as chamadas "cartas de ABC", estas firmaram uma tradição na história da escola primária brasileira. Mesmo sendo um utensílio originalmente vinculado a um dos mais tradicionais métodos de alfabetização (método sintético), nos termos de Mortatti (2000), resistiu às inovações promovidas pelos partidários de outros modelos de alfabetização, continuou sendo editado até os anos 50 do século XX.
} 
leitura e escrita e do que se considerou "todo" ou "parte", ao longo da história da alfabetização no Brasil, foi-se sedimentando a seguinte subdivisão classificatória desses métodos: métodos sintéticos (de marcha sintética): alfabético, fônico, silábico; e métodos analíticos (de marcha analítica): palavração, sentenciação, historieta, conto. (Mortatti, 2009, p. 94).

Desse modo, a silabação, que consistia na decomposição das palavras em sílabas, demandava o conhecimento de inúmeras sílabas isoladas para realizar a composição das palavras. Tal método também se fez presente na narrativa escolar da professora Ivana Farias Santos, quando estudou na "Escola isolada da professora Josefa Xavier", no município de Cumbi, entre 1952 e 1953:

[...] começava pelo a, e, i, o, u. Com a letrinha maior e depois com a letrinha menor. Depois vinha o $A B C$ maiúsculo e minúsculo. Depois vinham as sílabas... A gente ia apreendendo e quando a gente [gagueja] lia bem as sílabas, formava as palavras. Aí é que entrava na cartilha. Aí já era o que chamavam de primeiro ano adiantado, que a gente já lia, já estudava com a cartilha, já fazia a cópia de lição. [...] Aí a gente já começava a fazer o ditado. (Santos, 2013).

A lógica do método sintético preconizava o ensino da leitura a partir da pronuncia das letras e logo em seguida a reprodução do alfabeto na ordem em que os alunos decoravam, contudo, sem compreensão. Tais prerrogativas se contrapunham aos ventos da modernidade pedagógica, que traziam consigo o método de ensino analítico, que, por sua vez permitia o aprendizado da leitura por pequenas sentenças textuais, sem precisar antes aprender as letras e as sílabas. A negação dos métodos tradicionais e a apropriação do método analítico para a leitura ganhou força no estado de Sergipe com as ações do Diretor Geral da Instrução Pública, o médico e educador, Helvécio Ferreira de Andrade ${ }^{11}$. Seu discurso estava banhado pelo pensamento pedagógico paulista e pautava-se na crítica ao arcaico método existente. Segundo ele, a escola:

[...] clássica, tradicional, caracterizava-se pela passividade do mestre e do aluno. Aquele marcava a lição, que o discipulo devia recitar no dia seguinte, braços ao peito e olho na ferula. Uma palavra de menos ou de mais fazia jus a uma ou mais palmadas. [...] Foi em S. Paulo que deu o primeiro passo para a reforma dos métodos escolares, enviados á America do Norte uma turma de professores. Com Miss Brown à frente esses primeiros pioneiros do ensino publico, na Republica, organizaram a Escola Paulista, sob as diretrizes do método analitico. (Andrade, 1931, p. 10 - 11).

De modo geral, podemos asseverar que a proposição de "novos" métodos para o ensino da leitura e da escrita, nos estados, inclusive em Sergipe, fundamentou-se na negação ao antigo sistema de ensino, calcado nos processos de soletração e de silabação. Entretanto, a narrativa da professora Valdete Santana da Silva, quando evocou suas memórias da escola isolada no povoado "Tamanduá", atualmente município de Graccho Cardoso, no ano de 1933, nos revelou, sintomaticamente, a permanência do ensino da leitura e escrita pautado na repetição das lições ensinadas pelo professor: "[...] o método era esse, quando já conhecia as letras passava para a

\footnotetext{
${ }^{11}$ Helvécio Ferreira de Andrade foi o introdutor das ideias escolanovistas em Sergipe. Na condição de diretor da Instrução Pública, no período entre 1913-1918, 1926-1927, 1930-1935, ele contribuiu com a difusão dos conceitos médico-higienistas, pois este entendia higiene e educação como sinônimos de progresso.
} 
cartilha e estudava soletrando e repetindo. Depois o manuscrito, que era letra de mão. Era bem difícil, viu? Uma letrinha. Ave Maria! Quase a gente não descobria." (Silva, 2013). A professora Maria Doralice Ferreira, também narrou sobre as permanências do método sintético no mesmo cronótopo:

[...] quando o aluno sabia do $A B C$, que conhecia as letras, que já estava lendo... Já ouviu falar em manuscrito? Eu estudei manuscrito no tempo [1933]. Tinha uma leitura que o título era 'Brasil', precisava ter peito para ler, porque as letras eram bem miudinhas. Cada dia toda criança tinha que ler sua leitura. Era decorado, tudo gravado da memória. (Ferreira, 2013).

As narrativas das professoras revelaram a circulação do livro de leitura denominado Manuscrito. Tal impresso era utilizado nos momentos finais da instrução elementar e pressupunha a descodificação e treinamento de diversas caligrafias. Em contraponto, a Cartilha Analytica ${ }^{12}$, de Arnaldo Barreto, produzida desde 1906, "[...] não se trata[va] apenas de um método de alfabetização, mas o método mais geral, o intuitivo, que condiciona o formato dos textos." (Frade, 2011, p.190). Seus pressupostos preconizavam a apresentação de sentenças maiores para os alunos. Sendo assim, o ensino da leitura deveria ser iniciado pelo "todo", para depois se proceder à análise de suas partes constitutivas. A narrativa do professor Angelino Pereira de Moura sobre a Cartilha Analytica nos dá a ver a presença de tal impresso, bem como as dificuldades encontradas em sua apropriação:

[...] essa cartilha era a Cartilha Analytica. Era uma cartilha grande, começava pela lição. [reproduz trecho da cartilha] 'Paulo tem uma bola...' E quando eu fui... me apertei um pouco para ler, mas uma moça que me ensinava, dizia: 'Aqui é mais trabalhosa, não é cartilha para você não. Tem que ser outra. Pergunte a ela, se não pode ser outra.' Eu disse: 'Não, deixe aí para eu sair logo dessas cartilhas.' Aí na outra semana eu já sabia. Aí dei toda, a cartilha toda. Ela disse: 'Mas meu filho você tinha a cabeça dura e a cabeça ficou boa.' Eu disse: 'Quem muito ver, faz aprender.' (Moura, 2013).

Como insinua a narrativa de Angelino, a circulação e apropriação da Cartilha Analytica não se deu de forma linear. Contudo, é evidente o aspecto da agilidade e rapidez trazida pelo método. Sobre tal aspecto Hilsdorf (1994) considerou: "talvez a nota mais valorizada desses métodos fosse a rapidez com que a aprendizagem prometia ser realizada, a economia de tempo e de dinheiro nela implícita e o grande número de alunos que poderiam ser alcançados". (Hilsdorf, 1994, p.67). A velocidade das transformações sociais na época repercutiu, também no modo de ler e escrever, uma vez que a rapidez no traçado das letras, palavras e frases, constituiu o que ficou conhecido como caligrafia muscular. Nas palavras de Diana Vidal (2000), a caligrafia muscular prescrevia o ritmo regular do traçado da letra e a manutenção do lápis ou pena constante sobre o papel ou quadro. Os relatos do professor Angelino Pereira de Moura revelaram traços da caligrafia muscular, quando se reportou as suas memórias escolares na escola isolada no povoado "Campo Grande", localizado na cidade de Nossa Senhora das Dores, em 1933:

\footnotetext{
${ }^{12}$ A Cartilha Analítica, do professor Arnaldo de Oliveira Barreto (1869 - 1925), foi publicada pela editora Francisco Alves (RJ), com 1ạ. edição presumivelmente em 1909 e a última, a 74aㅡ, em 1967. A esse respeito, ver Bernardes (2008). Ao usar essa cartilha, o professor deveria proceder da seguinte maneira: primeiro, esclarecia sobre dez lições da cartilha por dez a trinta dias, depois, questionava e ouvia as respostas com o objetivo de provocar o discente a pensar e responder em linguagem clara.
} 
[...] ela [a professora] pegava na mão da gente com o giz. Ela dizia: 'Olhe... empurrando assim' [com inclinação]. Para nunca o giz deixar de escrever. Vai empurrando, empurrando e procurar a forma da letra. Todos os alunos sentados nas carteiras, segurando o lápis em cima dos cadernos [reproduz a voz da professora] 'Cubram as letras sem deixar o lápis sair do papel. E foi... até que eu desarnei ${ }^{13}$. (Angelino Pereira de Moura, 2013).

A caligrafia muscular despontou sob a tônica da modernidade, o que preconizava a rapidez e agilidade nos processos educativos. Tal caligrafia caracterizava-se por ser uma escrita de tipo inclinado, obtida pela tração em detrimento da pressão, resultado da união entre os músculos do antebraço e da mão. Outro aspecto preponderante é a postura adequada do corpo do aluno na carteira e a posição levemente oblíqua no traçado do lápis sobre caderno. Contudo, não podemos conceber que os ventos da modernidade sopraram com a mesma intensidade em todas as localidades do estado de Sergipe. Sobre as permanências em tempos de inovações, narrou Maria Menezes Oliveira, quando lecionou no Grupo Escolar "General Calazans", na cidade de Nossa Senhora das Dores, por volta de 1953:

[...] o estilo do ensino da época era aquele ensino rudimentar. Perverso... até de ter castigo físico. Tinham professores do grupo que diziam: 'Os alunos aprendem mais'. Depois começamos a participar dos treinamentos, do ano de sessenta, foi que mudou. Mas alguns professores continuaram. (Oliveira, 2013).

A narrativa da professora nos leva a fazer uma reflexão sobre as permanências dos métodos de ensino tradicionais em época de circulação do "novo" pensamento pedagógico, especialmente nos Grupos Escolares ${ }^{14}$, uma vez que as tentativas inovadoras dependiam, sobretudo, da reforma do pensamento do magistério, que, por sua vez estava correlacionadas ao alcance das políticas públicas de formação de professores. Para melhor condução no caminho em busca de compreender como os professores se apropriaram das proposições pedagógicas que circularam no estado de Sergipe, retomamos um questionamento: Os professores conheciam os "novos" pressupostos do magistério primário em cursos de formação, mais especificamente no Curso Normal e em Cursos de Aperfeiçoamento?

\section{A FORMAÇÃO DOS(AS) PROFESSORES(AS) E O ENSINO PELAS COISAS}

"Observação: ver, ouvir, tocar, apalpar."

(Andrade, 1931, p. 14).

O fragmento do relatório acima indica as transformações que deveriam ocorrer nos métodos de ensino nos primeiros vinte anos do século XX. Em tese, a escola tradicional deveria ceder espaço para o que propunha o projeto republicano. Desse modo, os Grupos Escolares eram concebidos enquanto um modelo ideal para a circulação e as apropriações das grandes novidades

\footnotetext{
${ }^{13}$ Esta palavra trata-se de um termo regional que significa desenvolver.

${ }^{14}$ Parafraseando Souza (1998), tratava-se de uma organização administrativa pedagógica mais complexa, concebida nos princípios da racionalidade científica e na divisão do trabalho. Assim, a racionalidade pedagógica fundamentavase na classificação dos alunos, no estabelecimento de um plano de estudos e na determinação da jornada escolar, resultando em um ensino mais homogênio, padronizado e uniforme.
} 
pedagógicas, a saber: o método de ensino intuitivo ${ }^{15}$. Tal modelo de instituição se colocava como emblema da República Brasileira, símbolo de modernidade e civilização, e que, em sua maioria, localizava-se nas capitais e cidades-polo ${ }^{16}$, servindo como vitrines das ações do Estado no campo da educação escolar e para os quais foram construídos suntuosos prédios. Nas palavras de Souza (1998), eram verdadeiros "Templos de civilização". Em sua concepção, os republicanos:

[...] deram à educação um lugar de destaque, sendo o grupo escolar representante dessa política de valorização da escola pública; dessa forma, eles conferiam a um só tempo: visibilidade à ação política do Estado e propaganda do novo regime republicano. [...]. Em certo sentido, o grupo escolar, pela sua arquitetura, sua organização e suas finalidades aliava-se às grandes forças míticas que compunham o imaginário social naquele período, isto é, a crença no progresso, na ciência e na civilização. (Souza, 1998, p.91).

Em detrimento das escolas isoladas, criadas convencionalmente nos perímetros suburbanos dos municípios, seriam suprimidas ou "deslocalizadas" pelos "majestosos" Grupos Escolares, lugares propícios para a aplicação do método intuitivo. Conforme Valdemarin (1998), para se obter um adequado resultado na utilização do método intuitivo, o ambiente escolar necessariamente deveria ser iluminado e arejado, ornamentados com trabalhos feitos pelos próprios alunos e nas salas de aula deveria ter um conjunto de material disponível para cada criança. (Valdemarin, 1998, p. 74). Sendo assim, o novo método teria, nos Grupos Escolares, condições de circular. A professora Maria Iolanda Araújo de Andrade testemunhou sobre as diferenças encontradas entre a Escola Isolada e o Grupo Escolar "General Calazans", construído em 1950 na cidade de Nossa Senhora das Dores:

[...] no ano de mil novecentos e cinquenta, foi inaugurado o Grupo Escolar 'General Calazans'. Todas as escolas isoladas foram transferidas para esse grupo. Eu saí de uma escola isolada, imprensada, apertadinha, cheia de gente, cheia de alunos. Para mim foi um grupo famoso. Era tudo pra mim! [exclamou emocionada] [...]. O 'General Calazans' era um lugar mais espaçoso, separado classe por classe, tinha recreio. E ali foi um ambiente mais confortável. Eu cheguei a fazer até a quarta série. [...] Tinha o mapa-múndi na parede, o mapa do Brasil, o mapa de Sergipe. (Andrade, 2013).

A professora Terezinha Rodrigues Aragão também destacou as diferenças entre o Grupo Escolar "Milton Azevedo" em relação às antigas escolas isoladas que lecionou, na cidade Aquidabã, em 1960:

[...] no grupo escolar era diferente das escolas isoladas. Tinha planos de aula, com os conteúdos. Era tudo planejado... os horários. Eu dava todo dentro do plano. Ainda sobrava tempo, eu dava aula de recreação, lá já tinha o pátio. No do Grupo

\footnotetext{
${ }^{15}$ Segundo Valdemarin (1998) as proposições do método de ensino intuitivo, que é adotado na segunda metade do século XIX nas escolas européias, americanas e brasileiras, circunscrevendo seu referencial teórico para além das formulações de Pestalozzi e Froebel, autores apontados como influenciadores do referido método nos manuais didáticos e nos compêndios de Pedagogia. Pestalozzi afirmavam a superioridade do método intuitivo consiste na colocação de fatos e objetos para serem observados pelos alunos, criando situação de aprendizagem em que o conhecimento não é meramente transmitido e memorizado mas, emerge no entendimento da criança a partir dos dados inerentes ao próprio objeto.

${ }^{16}$ Cidades com um desenvolvimento econômico e social acentuando.
} 
Escolar 'Milton Azevedo' já tinha globo, esqueleto humano. Tinha o mapa-múndi, o mapa do Brasil. Lá já era evoluído. (Aragão, 2013).

As narrativas de ambas as professoras nos apontam para traços do método intuitivo. Nas palavras de Valdemarin (1998), tal método considera os sentidos como janelas e portas que se abrem para um mundo interpretativo. Assim, os alunos do Grupo Escolar "General Calazans" e do Grupo Escolar "Milton Azevedo", ao observarem o esqueleto humano, mapas e globos, exercitavam o saber pelo mundo da observação. Os Grupos Escolares consistiam em escolas modelares onde era ministrado o ensino primário completo com um programa de ensino enriquecido e enciclopédico, utilizando os mais modernos métodos de ensino e processos pedagógicos existentes na época. (SOUZA, 1998, p. 70). Consequentemente, eles necessitaram de materiais compatíveis, a exemplo das caixas para ensino das cores e das formas, gravuras, coleções diversas, objetos variados de madeira, aros, linhas, papéis, entre outros, em substituição ao velho livro de textos.

É visível a preocupação com o material escolar nas mensagens de governadores. O "ensino pelas coisas" cobrava materiais de ensino em consonância com o método intuitivo. Nesta perceptiva o interventor federal, Dr. Eronides Ferreira de Carvalho em mensagem à Assembleia Legislativa em 7 de setembro de 1936, registrou as novas aquisições para as escolas públicas do Estado: “Distribuiu pelas escolas [...]: carteiras duplas, 279; bancas, 54; quadros negros, 46; contadores mechanicos, 68; livros, 87; mappas, 246; cadeiras, 53; cartas de linguagem, 50; cartas de Parker, 49." (CARVALHO, 1936, p. 40). Em complementaridade aos materiais, também era conveniente realizar visitas e viagens escolares nas adjacências da escola, com o intuito de ensinar pelas coisas. Encontramos os vestígios de tal estratégia de ensino nas narrativas do professor Angelino Pereira de Moura, quando lembrou dos os passeios escolares usados para o ensino das Ciências Físicas e Naturais na escola isolada de "Dona Antônia", no povoado "Malhada Pau Ferro", pertencente ao município de Feira Nova, entre os anos de 1934 e 1935:

[...] a Ciência aprendia... Olhe sobre folha. Tinha uma Ciência [livro] de Acrísio Cruz que ensinava. Eu sei que a gente fazia excursão e ia para um lugar longe assim, um rio, e fazia lá uma excursão. As plantas, aquelas folhas bonitas... Tem umas que é... [pausa de esquecimento] lanceoladas. Muitas... Eram assim de coração. E ali a gente ia dar aula, a gente podia pegar tudo que fosse de folha. Sabia? (Moura, 2013).

Os passeios lembrados pelo professor Angelino, quando aluno, remonta o ensino das Ciências Físicas e Naturais, que por sua vez pressupunha o estudo da natureza. As excursões ou viagens pedagógicas possibilitavam a aprendizagem por meio da observação. Assim, era primordial "ver", "observar" e "fazer", já que os defensores de tal método, segundo Faria Filho (2000), chamaram a atenção para a importância da observação das coisas, dos objetos, da natureza dos fenômenos e para a necessidade da educação dos sentidos, como fundamentais no processo de instrução escolar. No documento organizado pelo educador Lourenço Filho em 1933, intitulado: "O Ensino Primário no Brasil ", é visível no capítulo XXI a preocupação com as "lições de coisas" na Escola Primária no Estado de Sergipe:

[...] o horário de sábado é consagrado aos exercícios orais e escritos, lições de coisas baseadas nos <<centros de interesse >>, apreciação de <<diários infantis >>, sabatina, declamação, etc., devendo ser promovidos pelos professores ao menos 
uma vez por mês, as excursões aos parques, às fábricas e ao campo, a-fim-de instruir as crianças pela observação das coisas e fatos da vida. (Brasil, 1933, p. 13).

As prerrogativas do método intuitivo estavam ligadas aos princípios da Escola Ativa ${ }^{17}$, que por sua vez circulou no Estado de Sergipe pelo plano discursivo de Helvécio de Andrade: "Não mais a decoração pura e simples, a seca reprodução pelo aluno. [...] A escola era agora um comércio de ações e ideias entre o mestre e o discípulo, que podia perguntar, objetar, opinar, instruir-se, enfim: escola ativa." (Andrade, 1931, p. 11). As ações desse Diretor de Instrução Pública estavam em consonância com as inovações em âmbito nacional. No mesmo Relatório Anual, apresentado por ele ao governo interventorial à época, Augusto Maynard Gomes, pode-se ler:

[...] a grande ideia é o <<centro de interesse»>, como ponto de partida para observação, para análise, para generalização. De qualquer objeto faz o mestre um centro de interesse: um relógio, uma simples cadeira, um copo, a chuva, o vento, a árvore, o fruto, a semente... (Andrade, 1931, p. 12).

O modo de ensinar pelos exemplos do cotidiano privilegiavam as experiências e observações dos alunos, ou seja, pelos sentidos das coisas (relógio, cadeira, copo, chuva, vento, árvore, fruto, semente, entre outros) se chegaria ao conhecimento. Segundo Faria Filho (2000): "Tal etapa iniciava-se pelas "lições de coisas" ${ }^{18 ", ~ m o m e n t o ~ e m ~ q u e ~ o ~ p r o f e s s o r ~ d e v e ~ c r i a r ~ c o n d i c ̧ o ̃ e s ~}$ para que os alunos possam ver, sentir, observar os objetos." (Faria Filho, 2000, p. 143). Nesta perspectiva, a título de exemplo da apropriação do método, o professor Angelino Pereira de Moura utilizou dinheiro em espécie para tornar compreensível o ensino de Aritmética, na escola rural em "Feira Nova", no ano de 1956, era:

[...] cruzeiro e mil réis que eu usava. A gente ensinava pela forma das contas, multiplicar vinte por vinte e dois. Para somar aquele dinheiro. [retira o ábaco ${ }^{19}$ da estante e coloca no colo para explicar o ensino dos números] Também fazia outros tipos de conta pelo ábaco. Contava como se fosse o dinheiro das compras na feira. (Moura, 2013).

O ensino do referido professor, que se dava por meio de exemplos e situações do cotidiano são evidências do método intuitivo e evidencia parte do processo de sua circulação e apropriação. O método pressupunha a experimentação no contato com a natureza, bem como, as impressões provenientes da visão, da audição, do olfato e do tato eram imprescindíveis para aquisição do saber. O método possibilitava aos alunos o acesso a gravuras diversas, que tanto poderiam estar nos próprios livros e cartilhas distintos ou em cartazes especialmente produzidos para o trabalho com o método. Tais princípios, também circularam no estado de Sergipe na gestão do governador, Leandro Maynard Maciel. Sobre os objetivos do curso primário, no ano de 1956, ele assim relatou: "O objetivo dessa forma de instrução é procurar estimular o desenvolvimento da capacidade criadora da criança, da expressão clara de seu pensamento por meio do desenho, da pintura, da

\footnotetext{
17 Parafraseando Vidal (2000) o ideal da escola ativa é o mesmo ideal de Montaigne, de Locke e de Rousseau apropriados por Peslatozzi, Fichet e Froebel.

${ }^{18}$ Era pela visão, tato, audição, paladar e olfato que a criança seria levada a conhecer o mundo que o cercava. $O$ ensino seria realizado pelas "lições de coisas" - maneira como foi vulgarizado.

${ }^{19}$ Espécie de contador mecânico, que servia para fazer cálculos matemáticos de pequena dificuldade.
} 
modelagem, etc." (Maciel, 1956, p. 62). Nesse sentido, a escola deveria continuar oferecer situações em que o aluno, a partir da visão e experimentação pudesse construir seu próprio saber.

Após ter ouvido os doze professores narrarem sobre as apropriações e adequações dos métodos de ensino, bem como ter analisado os marcos normativos que revelaram a circulação do método intuitivo, adentramos pelo aspecto do ideal da formação dos professores. Nesse caminho encontramos indícios na mensagem apresentada em 1948, pelo governador José Rollemberg Leite, quando lançou um questionamento preocupante sobre a educação primária sergipana. Os motivos para tal preocupação se alicerçavam no desinteresse pela carreira do magistério, somada a falta de formação das professoras pela Escola Normal. Tal situação foi relatada com gravidade por José Rollemberg Leite:

[...] caso mais grave para Sergipe é o desinteresse pela vida magisterial. Êste ano, apenas 14 normalistas diplomadas solicitaram ingresso no professorado. Em face disto, o Departamento de Educação está se valendo de docentes de emergência, que não conhecem os métodos modernos, para que as escolas, em muitos casos, tenham, pelo menos a aparência de estarem regidas. Que qualidade é a de um ensino, ministrados por leigos submetidos a ligeira prova de habilitação! Finalmente, queremos educar ou deseducar os sergipanos? (Leite, 1948, p. IX).

No caso sergipano era a Escola Normal "Rui Barbosa" ${ }^{20 "}$ que estava direcionada a formar professores para o magistério primário. Nas palavras de Souza (1998), as Escolas Normais tinham por propósito serem, em cada estado: "templo de luz', o viveiro de onde sairiam os heróis anônimos da República." (Souza, 1998, p. 62). Dessa forma, o sucesso da escola renovada dependeria, pois, dos novos professores formados de acordo com as concepções educacionais modernas e de acordo com os valores republicanos. Para delinear o nível de formação dos(as) professores(as) envolvidos na pesquisa, elaboramos o quadro abaixo:

Quatro 1 - formação dos(as) professores(as) envolvidos na pesquisa.

\begin{tabular}{|l|c|c|c|c|}
\hline \multicolumn{1}{|c|}{ Professor(a) } & Curso Primário & Curso Ginasial & Curso Normal & Cursos/Treinamento \\
\hline Maria Iolanda Araújo de Andrade & $\mathrm{X}$ & & $\mathrm{X}$ \\
\hline Terezinha Rodrigues Aragão & $\mathrm{X}$ & & $\mathrm{X}$ \\
\hline Izabel Doracy Cardoso & $\mathrm{X}$ & $\mathrm{X}$ & $\mathrm{X}$ \\
\hline Maria Doralice Ferreira & $\mathrm{X}$ & & $\mathrm{X}$ \\
\hline Terezinha Feitosa de Melo & $\mathrm{X}$ & $\mathrm{X}$ & $\mathrm{X}$ \\
\hline Angelino Pereira de Moura & $\mathrm{X}$ & & $\mathrm{X}$ \\
\hline Maria Menezes de Oliveira & $\mathrm{X}$ & $\mathrm{X}$ & $\mathrm{X}$ \\
\hline Ivanda Farias Santos & $\mathrm{X}$ & $\mathrm{X}$ & & $\mathrm{X}$ \\
\hline
\end{tabular}

\footnotetext{
${ }^{20}$ A Escola Normal Rui Barbosa foi fundada em 1871 e em 1943 transformou-se no Instituto Pedagógico. Conforme o Relatório feito pelo Dro José Rollemberg Leite, apresentado em 1943 ao interventor do estado de Sergipe, Augusto Maynard Gomes, o Instituto Pedagógico "Rui Barbosa” oferecia uma formação enciclopédica com forte conteúdo de cultura geral, o curso tinha a duração de três anos, respectivamente: 1o ano - Português, Matemática, Física e Química, História Natural, História da Civilização Brasileira, Desenho Pedagógico, Educação Física, Canto Orfeônico, Trabalhos Manuais Pedagógicos. 2o ano - Biologia Educacional, Pedagogia, Agricultura e Economia Rural, Psicologia Infantil, Metodologia e Prática do Ensino Primário, Sociologia Educacional, Educação Física, Canto Orfeônico, Trabalhos Manuais Pedagógicos. 3 ano - História da Educação, Administração Escolas e Estatística, Psicologia Educacional, Metodologia e Prática do Ensino Primário, Agricultura e Economia Rural, Educação Sanitária e Higiene Escolar, Canto Orfeônico, Educação Física, Trabalhos Manuais Pedagógicos.
} 


\begin{tabular}{|l|c|c|c|c|}
\hline Maria Ducineia Souza Santos & X & X & X \\
\hline Odete Vieira dos Santos & X & X & X & X \\
\hline Terezinha Barbosa dos Santos & $\mathrm{X}$ & $\mathrm{X}$ & & $\mathrm{X}$ \\
\hline Valdete Santana da Silva & $\mathrm{X}$ & & & \\
\hline
\end{tabular}

Fonte: Memória Oral da Educação Sergipana.

O exposto no quadro, mesmo sendo uma amostra, nos revelou que poderiam legítimas as preocupações do governador José Rollemberg Leite, uma vez que parte dos entrevistados não ingressaram na Escola Normal "Rui Barbosa". Também é possível visualizar que as professoras Maria Iolanda Araújo de Andrade, Terezinha Rodrigues Aragão e Valdete Santana da Silva não cursaram o ginasial e apenas Terezinha Feitosa de Melo, já no fim da sua carreira, ingressou no Ensino Superior. Tais professores eram eleitos para o cargo com apenas o curso primário, a exemplo de Maria Ducineia Souza Santos, que no ano de 1947 se tornou professora por apenas saber ler, escrever e contar, no povoado "Papagaio", município de "Feira Nova". Relatou que:

[...] já sabia ler e escrever bem, as quatro operações. Eu com quinze anos, no ano de mil novecentos e quarenta e sete, o prefeito arrumou uma escola para mim. Eu estudei até a terceira série, mas ensinava até a quarta, mas meus alunos eram os melhores. Depois de muito tempo tirei o primário na cidade de Gararu. Eu não sou formada não. Tinha um curso lá de um mês, aí tirei o Ginásio. (Santos, 2013).

A narrativa da professora evidencia o baixo alcance do Curso Normal, mesmo em tempos em que o governo de Sergipe avançava em políticas educacionais, sobretudo cursos de aperfeiçoamento para o professorado primário. Tais cursos se desenvolviam sob a tônica da formação pedagógica. Contudo, esses deveriam ser de aperfeiçoamento e não necessariamente para cobrir uma lacuna - a formação no Instituto Pedagógico "Rui Barbosa", como aconteceu e vale ressaltar, de maneira apressada. A impossibilidade de realizar o Curso Normal se dava pelo fato de se tratarem de estudantes com baixo poder aquisitivo e na sua grande maioria eram casadas(os) e chefiavam suas famílias, fato que dificultava o deslocamento do Médio Sertão sergipano para a capital. A narrativa da professora Terezinha Rodrigues Aragão nos aponta este horizonte, na cidade de Aquidabã, nos idos de 1950:

[...] eu tinha uma vontade de fazer o Pedagógico [diz em tom de lamentação]. Aí não tinha. Depois 'Nicodemos Falcão' fundou o Ginásio, mas eu não fiz, não tinha condições financeiras também. $O$ prefeito conseguiu a portaria para mim no Grupo Escolar 'Milton Azevedo'. Aí eu fui fazer esses negócios do 'Colégio do Ar', ouvia pelo rádio. Os exercícios de 'Madureza ${ }^{21}$. A gente recebia as apostilas e fazia as provas no Atheneu [Sergipense]. A professora Maria Thetis Nunes me examinou. (Aragão, 2013).

A formação de professores deveria ser critério essencial para o ingresso na carreira do magistério. Contudo, havia uma dualidade entre o concurso público e a interferência política. $\mathrm{O}$

\footnotetext{
${ }^{21} \mathrm{Na}$ década de 1970, os governadores do estado de Sergipe continuaram investindo em cursos de preparação, treinamento e formação para professores, mas isso só foi possível através dos recursos provenientes do Plano Nacional de Educação (PNE), Instituto Nacional de Estudos e Pesquisas Educacionais Anísio Teixeira (INEP) e Programa de Aperfeiçoamento do Magistério Primário (PAMP), tal como da própria Secretaria do Estado de Sergipe. No ano de 1972, o então governador do Estado de Sergipe, Paulo Barreto de Menezes, implantou cursos para suprir a escassez de professores qualificados, dentre eles estavam o Curso de Preparação para Madureza Ginasial.
} 
concurso público para os cargos de professores primários que foi instituído em 1892 e para se inscrever o candidato deveria ter completado 18 anos, apresentar atestado de moralidade e, no caso do não diplomado ter exercido por 5 anos o magistério (Souza, 1996, p. 60). Como evidenciado, tais critérios foram desconsiderados na nomeação de Terezinha Barbosa dos Santos ao cargo de professora, em Nossa Senhora das Dores no ano 1945. Relembrou: "Eu tinha dezesseis anos só com o curso primário. $O$ candidato a prefeito aumentou a minha idade. Ele era dono do cartório, ele aumentou a minha idade e me deu um emprego de professora." (Santos, 2013). Maria Iolanda Araújo de Andrade, também testemunhou sobre os "apadrinhamentos" políticos em Nossa Senhora das Dores, em 1960:

[...] eu rezei foi muito, eu chorei muito. Eu pedindo ao político. Eu passava tanta vergonha, não tinha estudo, era quarto ano primário. Mas naquele tempo com o quarto ano, era professora. Os políticos quem dava [o cargo] para quem puxasse o saco. Ajudasse ele na campanha, não era por estudo não. [...] Entrei no ano de mil novecentos e sessenta, por causa de um irmão meu, que era vereador. Deram meu emprego, mas não foi por capacidade não [risos], foi com quarta série. (Andrade, 2013).

Pelas narrativas podemos conjecturar que a maioria dos professores(as) eram escolhidos(as) por prefeitos, vereadores, fazendeiros e por outras figuras que tinha poder local. Vale ressaltar que havia resistência de um(a) professor(a) da capital, com formação adequada, se deslocar para o interior do estado, bem como de um professor do interior ir a capital completa a formação solicitada. A professora Terezinha Feitosa de Melo narrou sobre a escassez de professores(as) formados(as) na cidade de Itabi, em 1950: “As professoras formadas pela Escola Normal não iriam sair de Aracaju para ensinar aqui. O prefeito colocava a gente só com o primário. Depois, quando estava perto de me aposentar fiz a faculdade de Pedagogia." (Melo, 2013). A narrativa nos apresentou diferenças que circunscreviam a formação dos professores da capital e do interior do Estado, para além de revelar as suas condições intelectuais, pois se caracterizavam por serem raramente diplomado e sem orientação didática, exercendo a docência a partir de suas experiências vividas.

Concebemos, assim como Rui Barbosa no século XIX, que não há como separar a formação de professores e o trabalho com métodos de ensino inovadores, pois a circulação e efetivação destes dependiam da forma como foram apropriados e adequados ao interior da sala de aula. No entanto, o professor se forma também pela prática, pela troca com seus pares, com seus alunos, e isso não tem como ser evidenciado pelos documentos, são as lacunas da história. Com isso, as narrativas aqui ouvidas são reveladores deste processo, entretanto há que se considerar que entre o ideal e o real há uma distância significativa em que necessariamente passam as condições de existência que por sua vez engloba o poder ser o poder fazer. Tais poderes estão por certo entre aquilo que está prescrito e aquilo que é possível e assim, caminhamos para uma resposta final, dentre as várias que o tema enseja.

\section{NA TRAVESSIA - A RESPOSTA FINAL}

Ao olhar para o mapa de Sergipe desdobrado em nossas mãos, concluímos que conhecemos novas pessoas e paisagens. Abandonamos o nosso lugar de origem e nos aventuramos rumo ao que queríamos conhecer. Em nossa viagem fomos direcionados pelos questionamentos acerca da circulação, das apropriações e das adequações dos métodos para o 
ensino da leitura, da escrita e do cálculo na escola primária no território do Médio Sertão sergipano, entre os anos de 1930 a 1961, encontramos a resposta no meio da travessia, uma vez que, os relatos orais e os documentos oficiais nos revelaram um denominador comum, que em processo de inovação, existem ressonâncias do passado. Nesse sentido, somos levados a concordar com as recomendações feitas por Mortatti (2006), em uma conferência sobre a história do ensino da leitura e escrita na fase inicial de escolarização de crianças. Segundo a autora, é preciso:

[...] conhecer aquilo que constitui e já constituiu os modos de pensar sentir, querer e agir de gerações de professores alfabetizadores (mas não apenas), especialmente para compreendermos o que desse passado insiste em permanecer. Pois é nas permanências, especialmente as silenciadas ou silenciosas, mas operantes, e nos retornos ruidosos e salvacionistas, mas simplistas e apenas travestidos de novo, que se encontram as maiores resistências. (MORTATTI, 2006, p. 15).

As permanências e rupturas que estiveram relacionadas à forma como os sujeitos escolares se apropriaram das proposições ditadas oficialmente produziram tensões entre as normas impositivas do Estado e a ação dos sujeitos, mediadas pelas condições de um e de outro dentro do processo de renovação escolar. A permanência do método sintético em tempos de circulação dos métodos analítico e intuitivo reforçou a antiga dicotomia entre velho e novo, tradicional e moderno, tão enraizada na educação brasileira.

Ficou evidente que mudanças nas relações espaciais, materiais, temporais e sociais estabelecidas no interior da escola primária no território do Médio Sertão sergipano contribuíram para determinadas apropriações e adequações dos métodos, pois se por um lado as leis e os normativos educacionais, nas primeiras décadas da república fizeram circular a recepção do método analítico e intuitivo, tal apropriação esteve sujeitos às formações dos(as) professores(as), aos repertórios que eles(as) mobilizam dentro de uma determinada época, às condições sociais e culturais do alunado, ao capital cultural construído, às experiências vividas, ao espaço escolar utilizado, à falta ou existência dos materiais de ensino, dentre outros elementos que nos levam a entender que não podemos escrever história da educação sem considerar a diversidade de fontes, as ideias pedagógicas e, sobretudo, as práticas escolares, pois é no cotidiano da sala de aula que professores e alunos aderem ou resistem, se apropriam ou subvertem o que é normatizado.

\section{REFERÊNCIAS}

Alberti, V. (2004). Manual de história oral. Rio de Janeiro; Editora FGV.

Albuquerque Júnior, D. Muniz. (2007). História: a arte de inventar o passado. Ensaios de teoria da História. Bauru, Edusc.

Andrade, M. I. A. (2013). Relato oral sobre sua história de vida. Entrevista concedida a Rony rei do Nascimento Silva. Nossa Senhora das Dores. 08 de maio.

Aragão, T. R. (2013). Relato oral sobre sua história de vida. Entrevista concedida a Rony rei do Nascimento Silva. Aquidabã. 11 de maio.

Brasil. (1933). O ensino Primário em Sergipe. In: O Ensino Primário no Brasil, vol XXI, INEP. São Paulo: Proprietária.

Bernardes, V. C. (2008). Um estudo sobre Cartilha Analytica, de Arnaldo de Oliveira Barreto (18691925). Revista de Iniciação Científica da FFC, v. 8, n.1, p. 1-17. 
Cardoso, I. D. (2013). Relato oral sobre sua história de vida. Entrevista concedida a Rony rei do Nascimento Silva. Aquidabã. 10 de maio.

Chartier, R. (1990). A História Cultural: entre práticas e representações. Rio de Janeiro, ed. Bertrand Brasil.

Faria Filho, L. M. (2000). Instrução elementar no século XIX. In: Lopes, E. Ma. T., Faria Filho, L. M., \& Veira, C. G. 500 anos de educação no Brasil. Belo Horizonte: Autêntica.

Ferreira, M. D. (2013). Relato oral sobre sua história de vida. Entrevista concedida a Rony rei do Nascimento Silva. Graccho Cardoso. 11 de maio.

Frade, I. C. A. S. (2011). História da alfabetização e da cultura escrita: discutindo uma trajetória de pesquisa. In: Mortatti, M. R. L. (Orgs.). Alfabetização no Brasil: uma história de sua história São Paulo. Marília: Cultura Acadêmica. Oficina Universitária.

Hilsdorf, M. L. S. (1994). Métodos de Educação Popular na Propaganda Republicana (1870-1889). Cadernos de História e Filosofia da Educação, v.II, n.3, São Paulo.

Le Goff, Jacques. (1996) História e Memória. 4. ed. Campinas: Unicamp.

Magnani, M. R. M. (1997). Os sentidos da alfabetização: a "questão dos métodos" e a constituição de um objeto de estudo (São Paulo, 1876-1994). 1997. 389 f. Tese (Livre-docência em Metodologia da Alfabetização) - Faculdade de Ciência e Tecnologia, Universidade Estadual Paulista, Presidente Prudente.

Mesquita, I. M., Barreto, R. A. D. N., Silva, R. R. N. (2013). O coser das memórias de aluna, de operária e de professora na roça: as experiências de Luzia Honória dos Santos. História Oral, v. 16, n. 2, p. 101-127, jul./dez.

Melo, T. F. (2013). Relato oral sobre sua história de vida. Entrevista concedida a Rony rei do Nascimento Silva. Itabi. 09 de maio.

Mortatti, M. R. L. (2000). Os Sentidos da Alfabetização: São Paulo-1876- 1994. São Paulo: Unesp.

Mortatti, M. R. L. (2016). Os órfãos do construtivismo. RIAEE - Revista Ibero-Americana de Estudos em Educação, v. 11, n. esp. 4, p.2267-2286.

Mortatti, M. R. L. (2009). A "querela dos métodos" de alfabetização no Brasil: contribuições para metodizar o debate. Revista Eletrônica Acolhendo a Alfabetização nos países de Língua Portuguesa (USP), v. 3, p. 91-114.

Moura, A. P. (2013). Relato oral sobre sua história de vida. Entrevista concedida a Rony rei do Nascimento Silva. Feira Nova. 07 de maio.

Oliveira, M. M. (2013). Relato oral sobre sua história de vida. Entrevista concedida a Rony rei do Nascimento Silva. Nossa Senhora das Dores. 06 de maio.

Pesavento, S. J. (2005). História \& história cultural. 2a Edição. Belo Horizonte: Autêntica.

Santos, L. D. (2016). Por uma história vista de baixo: as escolas primárias dos territórios do centro e sul do estado de Sergipe (1930 - 1960). 168f. Dissertação (Mestrado em Educação) Universidade Tiradentes, Aracaju.

Santos, I. F. (2013). Relato oral sobre sua história de vida. Entrevista concedida a Rony rei do Nascimento Silva. Cumbi. 08 de maio.

Santos, M. D. S. (2013). Relato oral sobre sua história de vida. Entrevista concedida a Rony rei do Nascimento Silva. Feira Nova. 07 de maio.

Santos, O. V. (2013). Relato oral sobre sua história de vida. Entrevista concedida a Rony rei do Nascimento Silva. Aquidabã. 09 de maio.

Santos, T. B. (2013). Relato oral sobre sua história de vida. Entrevista concedida a Rony rei do Nascimento Silva. Nossa Senhora das Dores. 06 de maio de 2013. 
Sergipe. (1931). Relatório Anual apresentado ao Governo Interventorial pelo Dr. Helvécio de Andrade, diretor geral, em 1931. Aracajú: Diretoria Geral da Instrução Publica e Normal. Relatório Anual/Empreza Typographica d'O Luctador,

Sergipe. (1936). Mensagem apresentada à Assembléia Legislativa, em 7 de setembro de 1936, pelo Dr. Eronides Ferreira de Carvalho em 1936. Aracajú: Imprensa Official.

Sergipe. (1943). Relatório apresentado ao Exmo. Sr. Interventor Federal Coronel Algusto Maynard Gomes pelo Diretor Geral do Departamento de Educaçã pelo Dr. José Rollemberg Leite, 1943. Aracajú: Diretoria Geral Do Departamento de Educação.

Sergipe. (1948). Mensagem apresentada à Assembleia Legislativa Estadual por ocasião da abertura da sessão legislativa de 1948, pelo Dr. José Rollemberg Leite, governador do estado de Sergipe. Aracajú: Diretoria Geral Do Departamento de Educação.

Sergipe. (1956). Mensagem apresentada à Assembléia Legislativa apresentada por Leandro Maynard Maciel, por ocasião da abertura da sessão ordinária de 1956. Aracajú: Imprensa Oficial.

Silva, V. S. (2013). Relato oral sobre sua história de vida. Entrevista concedida a Rony rei do Nascimento Silva. Graccho Cardoso. 10 de maio.

Souza, R. F. (1998). Templos de civilização: a implantação da Escola Primária Graduada no estado de São Paulo, 1890-1910; São Paulo: Fundação Editora da UNESP.

Valdemarin, V. T. (1998). Método Intuitivo: os sentidos como janelas e portas que se abrem para um mundo interpretado. In: Souza, R. F., Valdemarin, V. T., \& Almeida, J. S. O Legado Educacional do Século XIX. Araraquara: UNESP - Faculdade de Ciências e Letras.

Vidal, D. G. (2000). Escola Nova e Processo Educativo. In: Lopes, E. M. T., Faria Filho, L. M., \& Veira, C. G. 500 anos de educação no Brasil. Belo Horizonte: Autêntica. 